\section{The effect of self-efficacy and outcome expectation on medication adherence behaviour}

\author{
Senanu Okuboyejo, ${ }^{1}$ Victor Mbarika, ${ }^{2}$ \\ Nicholas Omoregbe ${ }^{1}$ \\ ${ }^{1}$ Department of Computer and \\ Information Sciences, Covenant \\ University, Nigeria; ${ }^{2}$ International \\ Center for IT and Development, \\ Southern University and A\&M, Baton \\ Rouge, LA, USA
}

\begin{abstract}
Medication adherence still ranks as a big challenge for clinicians and health workers. Based on a social learning theoretical framework, this study explores the adoption of patient adherence, medication adherence as a catalyst for improving the health and quality of life of individuals in Nigeria. Structural Equation Modelling technique was used to analyze the empirical data obtained. SLT variables including self-efficacy and outcome expectation were tested against medication adherence behavior. The constructs are related and positively correlated except definition which is contrary to previous researches. The research discusses these findings while also highlighting the implications for practice and policy.
\end{abstract}

\section{Introduction}

Medication adherence still ranks as a big challenge for clinicians and health workers. ${ }^{1}$ This work provides a healthbehavior theory-based approach to the study of medication adherence. Theories assist in the design of behavior change interventions in various ways: by promoting an understanding of health behavior, directing research and facilitating the transferability of an intervention from one health issue, geographical area or health care setting to another. ${ }^{2,3}$ Adherence to medications has been defined as the process by which patients take their medication as prescribed, described by three quantifiable phases: initiation, implementation, and discontinuation. ${ }^{4}$ Adherence to medical regimen is a complex behavioral issue especially to long term therapy in outpatient setting, hence, a theory will help to understand and conceptualize the problem. Theories also assist in the development of coherent interventions, thus, increasing transferability.
This study is focused not only on the adoption of specific behaviors, namely, patient adherence, but also the persistence in patient adherence as a catalyst for improving the health and quality of life of individuals in resource-poor regions, such as sub-Saharan Africa (SSA). Adopting the Social Learning Theory ${ }^{5}$ to conceptualize a research model, this study extends the work of Okuboyejo et al. ${ }^{6}$ Social learning (SLT) is a general theory that offers an explanation on the acquisition, maintenance, and change in criminal and deviant behavior. Social Learning Theory explains conforming or deviant behavior, abstinence, use and abuse of drugs as socially influenced behavior acquired and sustained through a learning process in which four main sets of variables operate. A sizable number of previous researches support SLT's postulations about the strong correlations between SLT variables and crime, delinquency, adolescent smoking and drug use. ${ }^{7-12}$ For example, SLT was used to generate psychosocial predictors of regimen adherence among persons with insulin-dependent diabetes mellitus (IDDM). ${ }^{13}$ The study revealed measures of expectancies and environmental support were reliably related to several adherence behaviors. A modified version of the Social Learning Theory of Personality (SLT) was used in an exploratory study on food behavior. ${ }^{14}$ Participants who believed they were in control of their destinies (internally-controlled) scored higher on reported nutritious food behavior than those who believed outcomes were due to outside forces (externally-controlled). In Okuboyejo et al. ${ }^{6}$ the SLT of medication adherence was explored. This theory was investigated in line with the SLT of Akers and Lee, ${ }^{5}$ and identified differential association (direct and indirect interaction with others), definitions, differential reinforcement and observational learning as the constructs. The findings from the research were consistent with reports in literature, hence, validating the appropriateness and suitability of the theory for adherence research.

\section{Materials and Methods}

\section{Research design}

Health behavior change generally involves 3 essential constructs: patient's readiness for change, perceived importance of change, and confidence in one's ability to change (self-efficacy). ${ }^{15}$ Self-efficacy and outcome expectancy have been investigated for restorative care activities, ${ }^{16}$ mathematical performance, ${ }^{17}$ teacher's orientation towards management, ${ }^{18}$ the implementation of instruction innovation, ${ }^{19}$ the use of web-
Correspondence: Senanu Okuboyejo, Department of Computer and Information Sciences, Covenant University, Ota, Ogun State, Nigeria.

Tel.: +234.8067601114.

E-mail: sena.okuboyejo@covenantuniversity.edu.ng

Key words: adherence, social learning theory, self-efficacy, outcome expectation.

Contributions: SO and VM conceived the idea and worked on the design. SO was responsible for data collection, and data analysis. SO and $\mathrm{NO}$ worked on the interpretation of results. SO drafted the article with input from NO, while VM and $\mathrm{NO}$ critically reviewed the article at different times, to ensure publication fit, quality and suitability. VM gave the final approval for publication.

Conflict of interests: the authors declare no potential conflict of interest.

Funding: CUCRID, Covenant University, Nigeria.

Received for publication: 30 November 2017. Accepted for publication: 10 July 2018.

This work is licensed under a Creative Commons Attribution NonCommercial 4.0 License (CC BY-NC 4.0).

(C) Copyright S. Okuboyejo et al., 2018 Licensee PAGEPress, Italy

Journal of Public Health in Africa 2018; 9:826 doi:10.4081/jphia.2018.826

based information systems, ${ }^{20}$ and among stroke survivors. ${ }^{21}$ The findings from these studies provided support for the relationship between self-efficacy, outcome expectation and behavior change. Self-efficacy for treatment adherence was identified as an important correlate of medication adherence in the treatment of HIV and other medical conditions. ${ }^{22}$ People are more likely to engage in certain behaviors when they believe they can execute those behaviors successfully (self-confidence). Outcome expectation refers to the expected consequences of one's own behavior. ${ }^{23,24}$ Several research works have also provided strong supports for the relationship between self-efficacy and outcome expectations. ${ }^{25-28}$ Therefore, in this work, we posit that confidence in one's ability to perform an action (self-efficacy) and the expectations that the behavior will have a desirable result (outcome expectations) are important mediators of performance of medication adherence behavior. Figure 1 represents the research model while Table 1 gives the meanings of the variables. 


\section{Research methodology}

A cross-sectional survey was used for this study. Data were collected by adopting quantitative methods using a questionnaire. The study population was adult Nigerians who were on any form of medication in outpatient settings. Our intention is to understand the adherence behavior of individuals on medications in outpatient setting. The study sample was a combination of random and convenience sample selected from major cities in the southwest region of Nigeria. This is beneficial in generalizing the study results. The survey instrument was adapted after that of Ronald Akers ${ }^{5}$ in the study of substance use among adolescents in Boys Town. The questions were rephrased to reflect the dependent and independent variables of medication adherence. Paper-based questionnaire and semi-structured interviews were used. Study participants were informed of their rights, benefits and risks by means of an informed consent letter, their right of confidentiality and that at no time should they disclose any information with which they felt uncomfortable. To maintain confidentiality, there was no identifying information on any questionnaire. The survey items were also translated to Yoruba for the benefit of those who could not read in English by a native speaker. The data collected were entered into Microsoft Excel 2007 exported into Partial Least Square (PLS) analysis software SmartPLS $2.0 \mathrm{M} 3$.

Six hundred copies of the questionnaire were distributed; four hundred and sixty copies were completed and returned. Ten cases were dropped because of incomplete responses for each of the measurement items. Ten cases were dropped because the respondents indicated they were not taking any form of medication. This left four hundred and forty (440) copies of the questionnaire for the statistical analysis, which represented a seventy-three per cent (73\%) valid return rate. Twenty copies had a response rate of eighty per cent $(80 \%)$; had instances of missing values. Mean substitution was used to generate the replacement values for the missing data of the construct. $^{29}$

\section{Results}

The formative model was assessed based on the indicator weights and variance inflation factor (VIF for multicollinearity). The indicator weights were estimated from the PLS Algorithm technique and significance measured by means of bootstrapping. A two-tailed t-test with 1.96 , and 2.576 critical values of $\mathbf{t}$ at significant levels (Pvalue) 0.05 , and 0.01 respectively was considered. The T-values of all the constructs were statistically significant at a minimum of 0.05 level $(\mathrm{P}<0.05, \mathrm{P}<0.01)$. The estimated VIF values are all less than 3.3, with condition indices ranging from 9 to 28 and are within the acceptable range for both parameters indicating the absence of multicollinearity. The coefficient of determination $\left(\mathrm{R}^{2}\right)$ of the structural model was measured as $12.5 \%$ while MASE predicts only $20.3 \%$ of the variation in OE. These $\mathrm{R}^{2}$ values are considered average from literature $\mathrm{e}^{30,31}$ and are represented in Table 2.

The Effect Size $\left(f^{2}\right)$ was estimated by means of Cohen's $f^{2}$. The significance of the $\mathrm{R}^{2}$ was measured using the following formula: ${ }^{32}$

$$
f^{2}=\frac{R^{2}}{1-R^{2}}
$$

The effect of all exogenous variables on the endogenous variable medication adherence behavior (MAB) is small, $\left(f^{2}=0.145\right)$; while the effect of all exogenous variables on the endogenous variable outcome expectation $(O E)$ is medium $\left(f^{2}=0.254\right)$. All path coefficients as shown in Table 3 below have positive correlation except for the path between definition (DFF) and medical adherence behavior (MAB).

All path coefficients are significant at $0.05(\mathrm{P}<0.05)$ except for path between $\mathrm{OL}$ and $\mathrm{MAB}$ is significant at $0.1(\mathrm{P}<0.1)$; paths between MASE and MAB, OE and MAB are not significant; and there is an indirect linear relationship between MASE and MAB via OE. The SEM technique was used to assess the structural model; this tested the

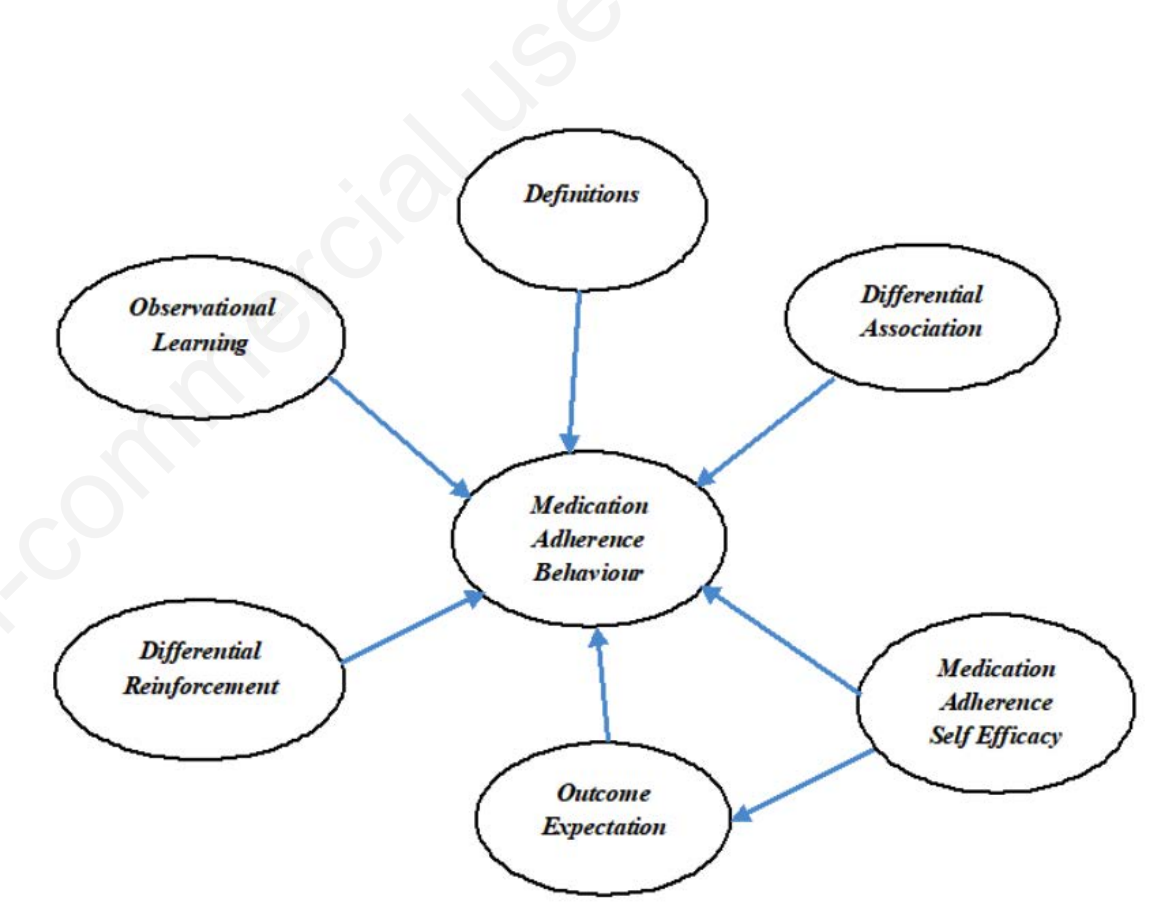

Figure 1. Research Model.

Table 1. Constructs from theory and definitions.

\begin{tabular}{|c|c|}
\hline Variable & Definition \\
\hline Differential Association & Individuals learn the values, attitudes, techniques, and motives for behavior through interaction with others. \\
\hline Definitions & An individual's own orientations, justifications, excuses and other attitudes that define the commission of an act. \\
\hline Differential Reinforcement & It refers to the balance of anticipated or actual rewards and punishments that follow or are consequences of an individual's behavior. \\
\hline Observational Learning & It refers to the engagement in behavior after the direct or indirect observation of similar behavior by others. \\
\hline Self-Efficacy & People are more likely to engage in certain behaviors when they believe they can execute those behaviors successfully. \\
\hline Outcome Expectation & Outcome Expectation refers to the expected consequences of one's own behavior. \\
\hline
\end{tabular}


effects among the seven (7) latent constructs (variables). Differential association $(\mathrm{P}<0.01)$, definition $(\beta=-0.2302, \mathrm{P}<0.01)$, differential reinforcement $\quad(\beta=0.183$, $\mathrm{P}<0.05)$, and observational learning $(\beta=0.1017, P<0.1)$ all had direct effects on medication adherence behavior at various levels; medication adherence self-efficacy (MASE) $\quad(\beta=0.0244, \quad \mathrm{P}>0.1, \quad \mathrm{P}>0.05$, $\mathrm{P}>0.01, \mathrm{P}>0.001)$ and outcome expectation $(\beta=0.0022, \quad P>0.1, \quad P>0.05, \quad P>0.01$, $\mathrm{P}>0.001$ ) had no direct effect on medication adherence behavior. MASE has a direct effect on outcome expectation $(\beta=0.4505$, $\mathrm{P}<0.001)$ with very strong support for the relationship between the two variables. Figure 2 represents the structural equation model with path coefficients calculated from the PLS-Algorithm technique.

\section{Discussion}

SLT is made up of differential association, differential reinforcement, observational learning and definitions. These constructs were tested against medication adherence behavior. The constructs are related and positively correlated except definition which is contrary to previous researches. Differential association was found to be a strong and significant predictor of medication adherence behavior, consistent with existing literature..$^{5,33,34}$ The measure of differential association is friend/peer association, which loaded strongest on differential association. To improve medication adherence behavior, patients should be exposed to close peers and friends who are perceived as adherent. The more they relate with them and get exposed to their normative beliefs, this behavior is learned and over time, this behavior becomes a way of life for them and even exerts influence on their relationship with friends. Definitions are one's own orientations, rationalizations, justifications, excuses, and other attitudes that define the commission of an act as relatively more right or wrong, good or bad, desirable or undesirable, justified or unjustified, appropriate or inappropriate. Specific definitions orient the person to acts or series of acts and to define given situations as providing opportunity or lack of opportunity for commission of crime. Findings from this work suggest that definitions will negatively affect medication adherence behavior. The more an individual's definitions, beliefs and rationalizations increases, the less the rate of medication adherence and vice versa. These findings suggest individuals should be made to understand the importance and need for adherence to their medication.

Differential reinforcement is a significant predictor of medication adherence behavior. The magnitude of the impact is quite low, but significance level indicates it as an important predictor. The hypothesis posits that the greater the value, frequency, and probability of reward for medication adherence, the greater the likelihood of medication adherence. To ensure completeness of medication, patients should be reinforced (rewarded) for successfully completing their medications. The question is How do we know patients who completed their medication? Medication bottles or containers could be fit with electronic caps and counters that keep a $\log$ of times it was opened, and number of drugs used. Moreover, this is not all encompassing, as the bottles could be opened without taking the medication. Health care personnel should endeavor to measure health outcomes over a period to determine the extent of adherence. Patients who adhered should be rewarded for such acts. Rewards can be in form of free medication or treatment at the patient's next visit. When patients are rewarded, there is the likelihood of improved adherence to medication. The direct/indirect observation of non-adherence behavior by others will influence a patient's rate of medication non-adherence. Observational learning refers to the engagement in behavior after the direct or indirect (e.g. in media depictions) observation of similar behavior by others. Findings show that a greater percentage of outpatients do not learn medication adherence behavior by observing others.

There is no support for the relationship between outcome expectation and medication adherence behavior contrary to literature. ${ }^{26,35}$ Also, the relationship between outcome expectation and medication adherence behavior was not supported in this

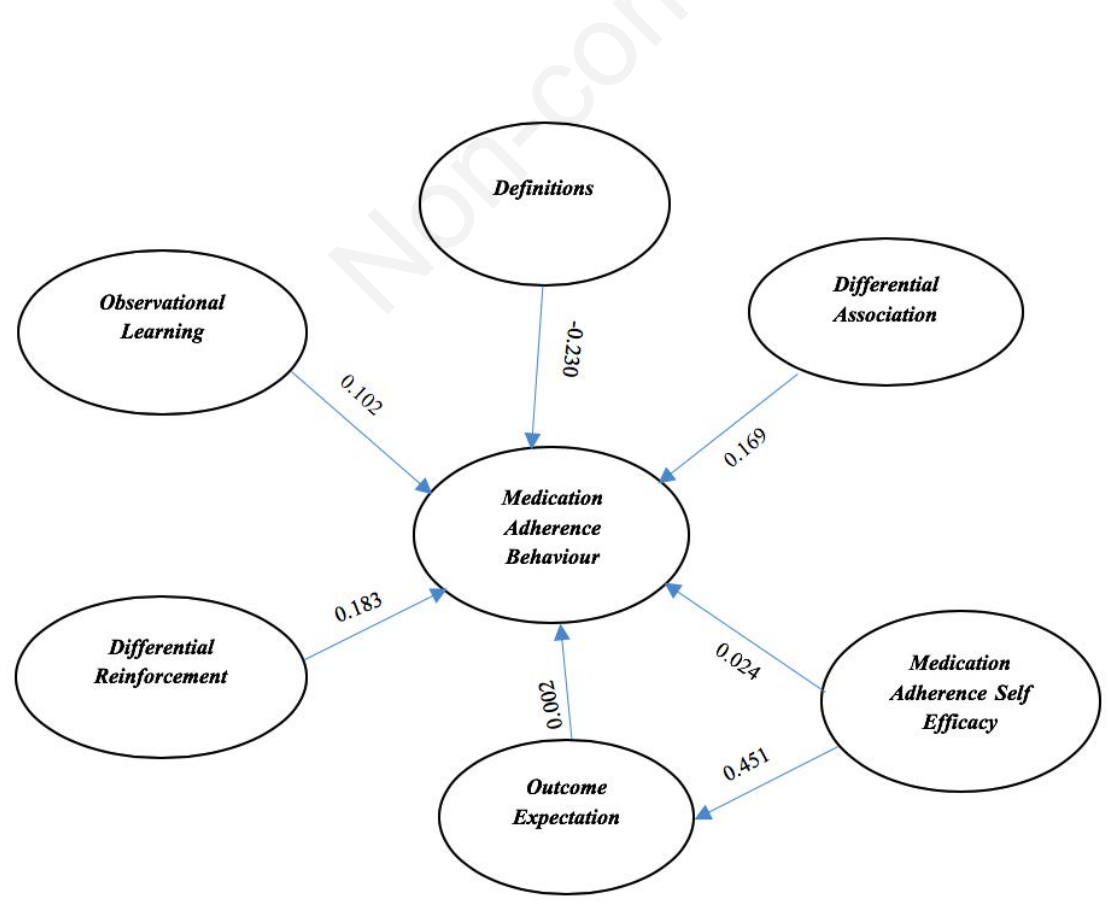

Figure 2. Path Analysis of the Research Model from PLS-Algorithm.

Table 2. Coefficient of determination (R2) of the structural model latent variables.

\begin{tabular}{lcc} 
& $\mathbf{R}^{2}$ & Redundancy \\
DA & 0 & 0 \\
DFF & 0 & 0 \\
\hline DR & 0 & 0 \\
MAB & 0.1254 & 0.0078 \\
\hline MASE & 0 & 0 \\
OE & 0.203 & 0.1146 \\
\hline OL & 0 & 0 \\
\hline
\end{tabular}

Table 3. Path coefficients of structural model latent variables.

\begin{tabular}{lcc} 
& MAB & OE \\
DA & 0.1689 & 0 \\
DFF & -0.2302 & 0 \\
\hline DR & 0.183 & 0 \\
MAB & 0 & 0 \\
\hline MASE & 0.0244 & 0.4505 \\
OE & 0.0022 & 0 \\
\hline OL & 0.1017 & 0 \\
\hline
\end{tabular}


study contrary to literature. People are more likely to engage in certain behaviors when they believe they can execute those behaviors successfully (self-confidence). The perceived self-efficacy plays an important role in influencing individuals' motivation and behavior. ${ }^{36-38}$ For our study, we infer that in outpatient settings, self-efficacy does not influence medication adherence behavior. This construct may be significant in controlled settings and randomized trials. However, in line with other works in literature, medication adherence self-efficacy was found to be a strong predictor of outcome expectation. Thus, there is an indirect relationship between medication adherence self-efficacy and medication adherence behavior.

\section{Conclusions}

Definitions will negatively affect medication adherence behavior. Individuals should be made to understand the importance and need for adherence to prescribed medication. Health care providers should improve provider-patient relationship. A good relationship will endear patients to their providers facilitating effective and efficient communication with feedback. Feedback suggests how well a patient understands what has been passed across. A thorough understanding of an illness or disease will build the patient's perception of such illness. A positive or negative perception will determine if such patient will adhere. The benefits, usefulness and health conditions that may arise because of medication adherence/non-adherence should be thoroughly taught. Outcome expectation may not be a predictor of medication adherence behavior in outpatient setting. Expected consequences of adherence behavior may not in any way motivate an individual to engage in that behavior without a prior understanding of medication adherence behavior. We suggest that patients be enlightened and educated on the need for medication adherence. Our findings highlight the importance of medication adherence self-efficacy and outcome expectation in medication adherence behavior learning and acquisition. Low self-efficacy will lead to a decline in an individual's differential association, differential reinforcement, imitation and definition. A decline in these social parameters will further lead to a decline in medication adherence self-efficacy. Since an individual's successful performance in other measured variables is a function of his level of self-efficacy and outcome expectation, there is a need to invest in programs and activities to boost medication-adherence self-efficacy and outcome expectation.

There is a need to also re-educate and sensitize the society at large on the implications of medication adherence. This could also be achieved through media sensitization, hospital/agencies sensitization and using ubiquitous technology devices such as mobile phones. The idea behind some of these types of programs is that by providing positive experiences and role models for non-adherent individuals, they are exposed to conventional norms and values that might diminish future deviant behavior. These approaches will work to cause behavioral change among the populace, and improving overall quality of life.

\section{References}

1. Rains JC, Lipchik GL, Penzien DB. Behavioral Facilitation of Medical Treatment for Headache-Part I: Review of Headache Treatment Compliance. Headache J Head Face Pain 2017;46: 1387-94.

2. Munro S, Lewin S, Swart T, Volmink J. A review of health behaviour theories: how useful are these for developing interventions to promote longterm medication adherence for TB and HIV/AIDS? Available from: https://implementationscience.biomedcentral.com/track/pdf/10.1186/14712458-7-104? site=implementationscience.biomedcentral.com

3. Redding CA, Redding CA, Rossi JS, et al. Health Behavior Models. Int Electron J Health Educ 2000;3:180-93.

4. Holmes E, Hughes D, Morrison V. Predicting Adherence to Medications Using Health Psychology Theories: A Systematic Review of 20 Years of Empirical Research. Value Health 2014; 17:63-76.

5. Akers R, Lee G. A Longitudinal Test of Social Learning Theory: Adolescent Smoking. J Drug Issues 1996;26:31743.

6. Okuboyejo S, Mbarika V, Omoregbe N. A Social Learning Theory of Medication Adherence in Nigeria: An Empirical Study. J Health Behav Public Health 2014; 1:37-44.

7. Krohn MD, Skinner WF, Massey JL, Akers RL. Social Learning Theory and Adolescent Cigarette Smoking: A Longitudinal Study. Soc Probl 1985;32:455-73.

8. Sellers C, Winfree T. Differential Associations and Definitions: A Panel Study of Youthful Behaviour. Int J Addict 1990;25:755-71.
9. Agnew R. A Longitudinal Test of Social Control Theory and Delinquency. J Res Crime Delinq 1991;2:126-56.

10. Agnew R. Why Do They Do it? An Examination of the Intervening Mechanisms between Social Control"Variables and Delinquency. J Res Crime Delinq 1993;30:245-66.

11. Warr M. Parents/Peers, and Delinquency. Soc Forces 1993;72:24764.

12. Mcgee GG, Almeida MC, SuimAzmrofp B, Fedman RS. Promoting reciprocal interactions via peer incidental teaching. J Appl Behav Anal. 1992

13. McCaul KD, Glasgow RE, Schafer LC. Diabetes Regimen Behaviors: Predicting Adherence [Internet]. Vol. 25, Medical Care. Lippincott Williams \& Wilkins; 1987. p. 868-81.

14. Houts S, Warland R. Rotter's social learning theory of personality and dietary behavior. J Nutr Educ 1989;21:172-9.

15. Rains JC, Lipchik GL, Penzien DB. Behavioral Facilitation of Medical Treatment for Headache-Part I: Review of Headache Treatment Compliance. Headache J Head Face Pain. 2006t46:1387-94.

16. Resnick B, Simpson M. Restorative care nursing activities: pilot testing selfefficacy and outcome expectation measures. Geriatr Nurs (Minneap) 2003;24:82-9.

17. Sexton TL, Tuckman BW. Self-beliefs and behavior: The role of self-efficacy and outcome expectation over time. Pers Individ Dif 1991;12:725-36.

18. Woolfolk AE, Rosoff B, Hoy WK. Teachers' sense of efficacy and their beliefs about managing students. Teach Teach Educ 1990;6:137-48.

19. Ghaith G, Yaghi H. Relationships among experience, teacher efficacy, and attitudes toward the implementation of instructional innovation. Teach Teach Educ 1997;13:451-8.

20. Yi MY, Hwang Y. Predicting the use of web-based information systems: selfefficacy, enjoyment, learning goal orientation, and the technology acceptance model. Int $\mathrm{J}$ Human-Computer Stud 2003;59:431-49.

21. Shaughnessy M, Resnick BM, Macko RF. Reliability and validity testing of the short self-efficacy and outcome expectation for exercise scales in stroke survivors. J Stroke Cerebrovasc Dis 2004;13:214-9.

22. Johnson M, Neilands TB, Dilworth SE, et al. The role of self-efficacy in HIV treatment adherence: validation of the HIV Treatment Adherence Self- 
Efficacy Scale (HIV-ASES). J Behav Med 2007;30:359-70.

23. Compeau DR, Higgins CA. Application of Social Cognitive Theory to Training for Computer Skills. Inf Syst Res 1995;6:118-43.

24. Compeau DR, Higgins CA. Computer Self-Efficacy: Development of a Measure and Initial Test. MIS Q 1995;19:189.

25.Compeau DR, Higgins CA. Application of Social Cognitive Theory to Training for Computer Skills. Inf Syst Res 1995;6:118-43.

26. Hsu MH, Ju TL, Yen CH, Chang CM. Knowledge sharing behavior in virtual communities: The relationship between trust, self-efficacy, and outcome expectations. Int $\mathrm{J}$ Hum Comput Stud 2007;65:153-69.

27. Johnson R, Marakas G. Research Report: The Role of Behavioral Modeling in Computer Skills Acquisition: Toward Refinement of the
Model. Inf Syst Res 2000;11:402-17.

28. Marakas GM, Johnson RD, Palmer JW. A theoretical model of differential social attributions toward computing technology: when the metaphor becomes the model. Int J HumanComputer Stud 2000;52:719-50.

29. Wu JH, Wang SC, Lin LM. Mobile computing acceptance factors in the healthcare industry: A structural equation model. Int $\mathrm{J}$ Med Inform 2007;76:66-77.

30. Chin W. The Partial Least Squares Approach to Structural Equation Modeling [Internet]. Marcoulides G, editor. London: Lawrence Erlbaum Associates; 1998. pp 295-336.

31. Urbach N, Ahlemann F. Structural Equation Modeling in Information Systems Research Using Partial Least Squares. JITTA 2010;11:5-40.

32. Selya AS, Rose JS, Dierker LC, et al. A Practical Guide to Calculating Cohen's $\mathrm{f}(2)$, a Measure of Local Effect Size, from PROC MIXED. Front Psychol 2012;3:111.

33. Boeringer S. Associations of RapeSupportive Attitudes with Fraternal and Athletic Participation. Violence Against Women 1999;5:81-90.

34. Akers RL, Lee G. Age, social learning, and social bonding in adolescent substance use. Deviant Behav J 1999;19:125.

35. Compeau DR, Higgins CA. Computer Self-Efficacy: Development of a Measure and Initial Test. MIS Q 1995;19:189.

36. Bandura A. Self-efficacy mechanism in human agency. Am Psychol 1982;37:122-47.

37. Bandura A. The Explanatory and Predictive Scope of Self-Efficacy Theory. J Soc Clin Psychol 1986;4:35973.

38. Igbaria M, Iivari J. The Effects of Selfefficacy on Computer Usage. Int J Mgmt Sci 1995;23:587-605. 